Original Article

\title{
The Effects of Horse Riding Simulation Training on Stroke Patients' Balance Ability and Abdominal Muscle Thickness Changes
}

\author{
IL-Hun BAeK, MS, PT ${ }^{1)}$, ByeOng Jo KIM, PhD, $\mathrm{PT}^{2 * *}$ \\ 1) Department of Physical Therapy, Dong-Eui Institute of Technology, Republic of Korea \\ 2) Department of Physical Therapy, Dong-Eui University: 176 Eomgwangno, Busanjin-gu, Busan \\ 614-714, Republic of Korea
}

\begin{abstract}
Purpose] The purpose of this study was to assess the effects of horse riding simulation training on changes in balance ability and abdominal muscle thicknesses of stroke patients. [Subjects] Thirty stroke patients with hemiplegia were recruited, and they were randomly assigned to a control or experimental group. [Methods] The experimental group performed horse riding simulation training, whereas the control group performed trunk exercises for 8 weeks. Balance ability was measured using a BioRescue system. The thicknesses of subjects' external oblique, internal oblique, and transversus abdominis muscles were measured by ultrasonic imaging. [Results] In the experimental group, balance ability was significantly improved after training. Similarly, the thickness of the abdominal muscles on the affected side changed after training in the experimental group, whereas the control group showed no statistically significant changes. [Conclusion] We suggest that horse riding simulation training is more effective than trunk exercises at reducing the center of pressure path length and travel speed and improving the asymmetry of the abdominal muscles of stroke patients.

Key words: Horse riding simulation training, Stroke, Abdominal muscles
\end{abstract}

(This article was submitted Jan. 20, 2014, and was accepted Feb. 22, 2014)

\section{INTRODUCTION}

Stroke is a disease that causes sudden local neurological deficit symptoms due to a cerebrovascular accident ${ }^{1)}$. Stroke may decrease postural control and balance ability due to sensory disability, motor disturbance, muscular weakness, and asymmetric postures resulting from central nervous system damage ${ }^{2}$. Reduced postural control and balance ability decreases overall physical function, making independent activities of daily living difficult for stroke patients, and increases the risk of falls. Therefore, improving stroke patients' balance ability is an important therapeutic objective ${ }^{3)}$. With regard to this issue, a recent cross-sectional study revealed that stroke patients' trunk control ability was correlated with balance, gait, and functional abilities ${ }^{4}$.

Exercises intended to improve stroke patients' trunk control have been extensively studied in recent years. Verheyden et al. ${ }^{2)}$ reported that a group of stroke patients that performed trunk exercises on plinths showed better improvement in trunk control than a group that received only conventional physical therapy. Pereira et al. ${ }^{5)}$ conducted trunk flexion and extension, and compared trunk muscle

*Corresponding author. Byeong Jo Kim (E-mail: pt123@deu. ac.kr)

C2014 The Society of Physical Therapy Science. Published by IPEC Inc. This is an open-access article distributed under the terms of the Creative Commons Attribution Non-Commercial No Derivatives (by-ncnd) License $<$ http://creativecommons.org/licenses/by-nc-nd/3.0/> activities measured by sEMG on the affected and unaffected sides of stroke patients. Karthikbabu et al. ${ }^{6}$ studied the effect of exercise using Swiss balls on the improvement of trunk muscles. Although many exercise programs for trunk control have been implemented, there are few programs that can improve subjects' balance while maintaining their interest. Exercise programs using horse riding have been developed recently. Horse riding programs elicit active trunk and motivate subjects.

After the first horse riding studies were performed with patients with neurological damage, hippotherapy was used only to treat children with neurological disorders, mainly cerebral palsy, to improve their postural control and promote their normal development and functional recovery ${ }^{7,8)}$. The horse's gait is repetitive and rhythmic, and causes the center of gravity to move in anterior-posterior, lateral, and upward-downward directions. Since the patterns of these movements are similar to those of the movements of the trunk and pelvis during human gait, such exercise is expected to make the subjects feel as if they were walking ${ }^{9)}$. Hippotherapy is effective in terms of psychological motivation because it arouses subjects' interest in participating in the therapy ${ }^{9,10)}$, and helps in the recovery of many physical functions. Hippotherapy increases the range of joint motion, strengthens muscles, and improves muscle tone, postural control, and balance and equilibrium ability. Improvements in postural control and balance ability are achieved through stimulation of the upper motor neurons through proprioceptive sensory stimulation inputs ${ }^{11,12}$. Despite these therapeu- 
tic effects, no studies have been conducted on the changes in muscles related to stroke patients' stability and balance after hippotherapy. In this study, the improvement in stroke patients' trunk control and changes in abdominal muscle thicknesses after horse riding simulation training were examined.

\section{SUBJECTS AND METHODS}

The purpose of this study was explained to patients diagnosed with stroke at D General Hospital in Busan, South Korea. Patients willing to participate in the study were recruited, and those who satisfied the selection criteria were randomly assigned to a control or experimental group (15 patients per group).

Subject selection criteria were as follows: patients with hemiplegia and no previous experience with hippotherapy who could follow verbal instructions, sit and walk independently (regardless of the use of walking aids), and had no restriction in the range of joint motion.

Both groups received central nervous system developmental therapy for $30 \mathrm{~min}$. Then, the experimental group performed horse riding simulation training, while the control group performed trunk exercises using Swiss balls. Training was performed for $30 \mathrm{~min}$ per session, three sessions per week for a total of eight weeks ${ }^{10)}$. The subjects were evaluated before the intervention and after eight weeks of training. The general characteristics of the study subjects are shown in Table 1.

All subjects agreed in writing to participate in this study after receiving a detailed explanation of the experimental procedure, and possible side effects of the intervention. The experiment was conducted after receiving approval from the Human Subjects Research Ethics Committee of DongEui Medical Center (DEMCIRB-2013-1001).

The horse riding simulator (EU6441 Core Muscle Trainer; Panasonic, Japan) used is designed to simulate the effects of horse riding exercises in an indoor environment using three-directional movements (anterior-posterior, lateral, upward-downward), and has three different programs and nine levels of exercise intensity. A therapist and an assistant monitored each subject during horse riding training.

A balance ability measuring and training system (an analysis system with biofeedback, AP1153; BioRescue, France) was used to evaluate subjects' balance ability. Static balance ability (center of pressure [COP] path length and COP travel speed) was measured while subjects stood for $60 \mathrm{~s}$ with their eyes open. The subjects were prevented from seeing the monitor to avoid visual feedback, and the position of the feet was maintained during repeated measurements to eliminate errors resulting from changes in foot positions. All tests were performed three times, and average values were calculated.

Ultrasonic imaging equipment (Sonoace X4; Medison, Korea) was used to measure the thicknesses of the abdominal muscles on both sides. Ultrasonic images were collected using $7.5 \mathrm{MHz}$ linear probes. Subjects were instructed to bend their knees to $90^{\circ}$ and to maintain a comfortable posture in a supine position. Linear probes were positioned on
Table 1. Subjects' general characteristic $(n=30)$

\begin{tabular}{lcc}
\hline Group & $\begin{array}{c}\text { Control group } \\
(\mathrm{n}=15)\end{array}$ & $\begin{array}{c}\text { Experimental } \\
\text { group }(\mathrm{n}=15)\end{array}$ \\
\hline Age (years) & $56.5 \pm 7.5$ & $55.1 \pm 6.1$ \\
Height $(\mathrm{cm})$ & $163.3 \pm 8.2$ & $165.1 \pm 8.5$ \\
Weight $(\mathrm{kg})$ & $63.5 \pm 8.5$ & $65.4 \pm 9.8$ \\
Sex (male/female) & $8 / 7$ & $7 / 8$ \\
Cause of brain damage & & \\
(cerebral hemorrhage & $8 / 7$ & $6 / 9$ \\
/cerebral infarction) & & \\
Affected side (right/left) & $9 / 6$ & $10 / 5$ \\
\hline
\end{tabular}

Data are mean \pm SD

both sides, midway between the bottom of the rib cage and the top of the iliac crest. Images were collected at the end of expiration $^{13)}$. The thicknesses of the external oblique, internal oblique, and transversus abdominis muscles were measured three times and their average values were calculated.

The data were processed using the SPSS 18.0 program. The paired t-test was conducted to compare the results before and after the intervention within each group and the independent t-test was used to compare the exercise and control groups before and after the experiment. Significance was accepted for values of $\alpha<0.05$.

\section{RESULTS}

The experimental but not the control group showed statistically significant differences $(p<0.01)$ between the COP path lengths of before and after the intervention. The differences between the two groups were not significant before the experiment, but were statistically significant $(\mathrm{p}<0.05)$ after the intervention (Table 2).

The experimental, but not the control group, showed statistically significant differences $(p<0.05)$ between the speeds of the COP travel of before and after the intervention. There was no significant difference between the control and the experimental group before the experiment, but the speed of COP travel decreased more in the experimental group than in the control group after the experiment, and this difference was statistically significant $(\mathrm{p}<0.05$; Table 2).

Changes in abdominal muscle thicknesses after training were observed in the experimental group. Before training, TrA and IO did not show any significant differences between the affected and unaffected sides. In contrast, EO showed significant differences: $5.7 \pm 1.6 \mathrm{~mm}$ on the unaffected side and $4.7 \pm 1.4 \mathrm{~mm}$ on the affected side $(\mathrm{p}<0.05)$. After eight weeks of training, TrA, IO, and EO on the unaffected side did not show any changes compared to before the training.

TrA and IO on the affected side did not show any changes after training, but the EO thickness significantly increased from $4.7 \pm 1.4 \mathrm{~mm}$ to $5.2 \pm 1.6 \mathrm{~mm}$. Total abdominal muscle thickness differed significantly before training between the affected and unaffected sides $(13.5 \pm 2.7 \mathrm{~mm}$ and $14.3 \pm 3.0 \mathrm{~mm}$, respectively). After eight weeks of train- 
Table 2. Changes in static balance following horse riding simulation training

\begin{tabular}{llrc}
\hline & Group & Pre-test & Post- test \\
\hline Center of pressure & Control & $14.5 \pm 5.9$ & $14.4 \pm 5.8$ \\
path length (cm) & Experimental & $15.9 \pm 5.1$ & $12.2 \pm 4.3^{\text {a }}$ \\
Center of pressure & Control & $0.7 \pm 0.3$ & $0.7 \pm 0.2$ \\
travel speed $(\mathrm{mm} / \mathrm{s})$ & Experimental & $0.7 \pm 0.3$ & $0.6 \pm 0.2^{\text {a }}$ \\
\hline
\end{tabular}

${ }^{a}$ Different superscripts within the same columns indicate significant differences $(\mathrm{p}<0.05)$

ing, both sides showed slight increases, with final values of $14.1 \pm 2.9 \mathrm{~mm}$ on the affected side and $14.3 \pm 5.8 \mathrm{~mm}$ on the unaffected side, but these differences were not statistically significant ( $p>0.05$; Table 3 ).

\section{DISCUSSION}

This study examined the effects of horse riding simulation training on the improvement of balance ability (which is an important issue for stroke patients), and the changes in abdominal muscle thicknesses of stroke patients. The distance and speed of center of gravity movements were measured using a Biorescue system, and changes in abdominal muscle thicknesses were observed by ultrasonography.

The COP path lengths of before and after the intervention were similar in the control group ( $\mathrm{p}>0.05)$, but significantly decreased in the experimental group after horse riding training. The changes in the speed of COP travel showed that body sway remarkably decreased in the experimental group after training in comparison with the control group. These changes presumably occurred because the trunks of the subjects became more stable as a result of horse riding simulation training, reducing body sway and shaking.

Regarding abdominal muscle thicknesses, EO was thinner before training on the affected side than on the unaffected side, resulting in a difference in total abdominal muscle thickness on the affected and unaffected sides. This is consistent with the results of the study by English et al. ${ }^{14)}$, which measured the abdominal muscles of stroke patients (65 years old or older) at rest. Although the mean age of the subjects in our present study was somewhat lower (55.1 \pm 6.1 years), similar results were obtained.

EO showed differences between the affected and unaffected sides before the experiment. Even though EO is mainly mobilized during trunk rotation movements, Pereria et al. ${ }^{5)}$ reported that EO was activated when stroke patients performed exercises that involved lifting of both legs, and this reportedly occurred to compensate for the inactivity of the rectus abdominis. Similarly, in our present study the EO muscle may have activated more to compensate for the weakness of the rectus abdominal muscles on the affected side of the stroke patients. Another reason for higher EO activation on the affected side could be that it is located closer to the surface layer than TrA and IO, which would affect thickness changes because horse riding simulation exercises induce multi-directional movements.

Although diverse balance training programs for stroke patients have been reported, therapeutic approaches using
Table 3. Changes in abdominal muscle thickness following horse riding simulation training (experimental group; $\mathrm{n}=15$ )

\begin{tabular}{lllr}
\hline & Side & Pre-test & Post-test \\
\hline \multirow{2}{*}{ TrA } & A & $2.5 \pm 0.8$ & $2.7 \pm 0.9$ \\
& NA & $2.5 \pm 0.6$ & $2.6 \pm 0.6$ \\
IO & A & $6.3 \pm 0.15$ & $6.3 \pm 1.6$ \\
& NA & $6.0 \pm 0.16$ & $6.1 \pm 1.8$ \\
EO & A & $4.7 \pm 1.4^{\mathrm{a}}$ & $5.2 \pm 1.6$ \\
& NA & $5.7 \pm 1.6$ & $5.7 \pm 1.4$ \\
\multirow{2}{*}{ Total } & A & $13.5 \pm 2.7$ a & $14.1 \pm 2.9$ \\
& NA & $14.3 \pm 3.0$ & $14.3 \pm 5.8$ \\
\hline
\end{tabular}

A, affected side; NA, non-affected side; abdominal muscle thicknesses unit: $\mathrm{mm}$. Different superscripts within the same columns indicate significant differences $(p<0.05)$

horse riding have rarely been studied with stroke patients as subjects. Some studies have been conducted with persons with neurological disorders, in particular children with cerebral palsy ${ }^{7,8)}$. Therefore, comparison of our present results with those of previous studies was difficult. Future studies of horse riding simulation may lead to an improvement in stroke patients' balance ability. Horse riding simulation training can be fun and interesting for patients, which may increase their motivation to actively participate in exercise program and thus enhance the improvement of neurologic functions ${ }^{9,10)}$. Therefore, it should be studied further.

Our experiment had several limitations. First, only subjects who could sit independently were selected. Second, ultrasonic measurement was conducted in a steady state in a supine position. Third, since the damaged sites and symptoms differed among subjects, standard subjects could not be selected. Fourth, various medical interventions implemented by clinics could not be properly controlled. Therefore, in future studies, the effects of hippotherapy on stroke patients should be examined with a more efficient control and the selection of a wide range of subjects. Additional information should be provided by comparison (during ultrasonic measurement) of the degrees of contraction on the affected and unaffected sides.

In conclusion, horse riding simulation training may reduce the distance and speed of the center of gravity movements of stroke patients and reduce the asymmetry of the abdominal muscles. To improve stroke patients' balance ability, diverse uses of horse riding simulation training should be considered.

\section{ACKNOWLEDGEMENT}

This research was supported by a research grant (2013 Academic Expense Grant 2013AA096) from Dong-Eui University.

\section{REFERENCES}

1) Ryerson S, Byl NN, Brown DA, et al.: Altered trunk position sense and its relation to balance functions in people post-stroke. J Neurol Phys Ther, 
2008, 32: 14-20. [Medline] [CrossRef]

2) Verheyden G, Vereeck L, Truijen S, et al.: Trunk performance after stroke and the relationship with balance, gait and functional ability. Clin Rehabil, 2006, 20: 451-458. [Medline] [CrossRef]

3) Yavuzer G, Eser F, Karakus D, et al.: The effects of balance training on gait late after stroke: a randomized controlled trial. Clin Rehabil, 2006, 20 960-969. [Medline] [CrossRef]

4) Verheyden G, Nuyens G, Nieuwboer A, et al.: Reliability and validity of trunk assessment for people with multiple sclerosis. Phys Ther, 2006, 86: 66-76. [Medline]

5) Pereira LM, Marcucci FC, de Oliveira Menacho M, et al.: Electromyographic activity of selected trunk muscles in subjects with and withou hemiparesis during therapeutic exercise. J Electromyogr Kinesiol, 2011, 21: 327-332. [Medline] [CrossRef]

6) Karthikbabu S, Nayak A, Vijayakumar K, et al.: Comparison of physio ball and plinth trunk exercises regimens on trunk control and functiona balance in patients with acute stroke: a pilot randomized controlled trial. Clin Rehabil, 2011, 25: 709-719. [Medline] [CrossRef]

7) Kang KY, Song BH: Effects of horseback riding simulation machine training on gross motor function for the children with cerebral palsy. J Korea Contents Assoc, 2010, 10: 268-284. [CrossRef]

8) Liptak GS: Complementary and alternative therapies for cerebral palsy. Ment Retard Dev Disabil Res Rev, 2005, 11: 156-163. [Medline] [Cross-
Ref]

9) Debuse D, Gibb C, Chandler C: Effects of hippotherapy on people with cerebral palsy from the users' perspective: a qualitative study. Physiother Theory Pract, 2009, 25: 174-192. [Medline] [CrossRef]

10) Benda W, McGibbon NH, Grant KL: Improvements in muscle symmetry in children with cerebral palsy after equine-assisted therapy (hippotherapy). J Altern Complement Med, 2003, 9: 817-825. [Medline] [CrossRef]

11) Sterba JA, Rogers BT, France AP, et al.: Horseback riding in children with cerebral palsy: effect on gross motor function. Dev Med Child Neurol, 2002, 44: 301-308. [Medline] [CrossRef]

12) Cunningham B: The effect of hippotherapy on functional outcomes for children with disabilities: a pilot study. Pediatr Phys Ther, 2009, 21: 137138, author reply 137-138. [Medline] [CrossRef]

13) Urquhart DM, Barker PJ, Hodges PW, et al.: Regional morphology of the transversus abdominis and obliquus internus and externus abdominis muscles. Clin Biomech (Bristol, Avon), 2005, 20: 233-241. [Medline] [CrossRef]

14) English CK, Thoirs KA, Fisher L, et al.: Ultrasound is a reliable measure of muscle thickness in acute stroke patients, for some, but not all anatomical sites: a study of the intra-rater reliability of muscle thickness measures in acute stroke patients. Ultrasound Med Biol, 2012, 38: 368-376. [Medline] [CrossRef] 